\title{
Turning dilemmas into opportunities: a UNU/SCN capacity development network in public nutrition in Central and Eastern Europe
}

\author{
Mirjana Pavlovic ${ }^{1, *}$, Fré Pepping ${ }^{2}$, Michal Demes ${ }^{3}$, Lajos Biro ${ }^{4}$, Peter Szabolcs ${ }^{4}$, Zlatka \\ Dimitrovska $^{5}$, Vesselka Duleva ${ }^{6}$, Camelia Parvan$^{7}$, Aida Filipovic Hadziomeragic $^{8}$, \\ Maria Glibetic ${ }^{1}$ and Arne Oshaug ${ }^{9}$ \\ 'Nutrition Department, Institute for Medical Research, University of Belgrade, Tadeusa Koscuskog 1, Belgrade \\ 1 1000, Serbia: ${ }^{2}$ The Graduate School VLAG, Wageningen University, Wageningen, The Netherlands/United \\ Nations University Food \& Nutrition Programme: ${ }^{3} \mathrm{FAO}$ Sub-Regional Office for Central and Eastern Europe, \\ Budapest, Hungary: ${ }^{4}$ National Institute of Food Safety and Nutrition, Budapest, Hungary: ${ }^{5}$ Republic Institute for \\ Health Protection, Skopje, Macedonia: ${ }^{6}$ National Centre of Public Health Protection, Sofia, Bulgaria: ${ }^{7}$ Institute of \\ Public Health, Bucharest, Romania: ${ }^{8}$ Institute of Public Health of Federation of Bosnia and Herzegovina, \\ Sarajevo, Bosnia and Herzegovina: ${ }^{9}$ Akershus University College, Lillestrom, Norway
}

Submitted 1 September 2007: Accepted 28 0ctober 2008: First published online 6 February 2009

\begin{abstract}
Capacity development in nutrition is a process whereby individuals, groups, institutions, organizations and societies enhance their abilities to identify and meet challenges in a sustainable manner. To address these issues, in 2001 the UN System Standing Committee on Nutrition ( $\mathrm{SCN}$ ) established a Working Group on Capacity Development under the joint coordination of the United Nations University (UNU) and the International Union of Nutritional Sciences. Several regional professional networks have developed under this working group, the latest for the Central and Eastern Europe (CEE) countries. Ten CEE countries formed a network in 2006 and identified major nutritional challenges in the region, which included: irregular meal patterns; low consumption of fruits/vegetables, milk products and fish; low intake of some micronutrients; and high intakes of fat, sugar and salt. Public policies in nutrition were either weak or absent. Some countries had recently developed nutrition plans. Higher education in nutrition was seen as very important for public nutrition work by professionals in the region, who considered it a prerequisite for reversing the negative trend of the nutrition transition. The network will continue to work on issues that are still not covered adequately. Its activities to date and prospects for the future are assessed against ten principles for good capacity development suggested by the United Nations Development Programme.
\end{abstract}

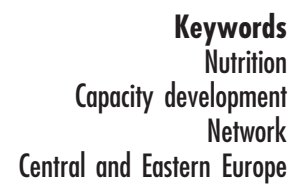

The United Nations University (UNU) Food and Nutrition Programme (FNP) and the International Union of Nutritional Sciences (IUNS) have cooperated on a global initiative to enhance institutional and professional capacity in the area of food and nutrition since 1996. A workshop on 'Institution Building for Research and Advanced Training in Food and Nutrition in Developing Countries' was held in Manila, Philippines in August $1996^{(1)}$. Subsequently the IUNS and UNU decided to focus their initial efforts on Africa by holding regional workshops in Southern, Eastern and Western and Central Africa for the purpose of developing 10-year action plans for capacity building for Africa.

Parallel to the UNU/IUNS initiative, a special Working Group on Capacity Development (WG) was established under the UN System Standing Committee on Nutrition (SCN) at its annual meeting in Washington DC in 2000. Working groups are the driving force of the SCN. They allow participants to take an active role in the work programme of the SCN, which is aimed at harmonizing professional viewpoints, information sharing, advocacy and reviewing issues important to the SCN. Currently there are nine such SCN working groups. $\uparrow$ The WG was established in collaboration with the UNU and reflects the SCN's endorsement of capacity development (CD) as one

\footnotetext{
$\dagger$ More information on the working groups in the SCN is available online at http://www.unsystem.org/scn/Publications/AnnualMeeting/working groups.htm. More explanation about the organization, its activities and products are available online at http://www.unsystem.org/scn/
} 
of its major foci. A first WG meeting was scheduled for the 29th SCN annual meeting in Nairobi, Kenya, in April 2001, which reported on three workshops in Africa. The SCN/ UNU WG also initiated regional networks in Asia, Latin America and the Middle East besides Southern Africa ${ }^{(2-4)}$. The regional networks seem well-organized and active, although functioning at different levels of activity.

$\mathrm{CD}$ is used in various ways; it is therefore important to be clear on what is meant when using the term. CD in food and nutrition is understood here as more than formal training. It includes the development of both human resources and organizational, institutional and legal frameworks with the aim of enhancing knowledge and skills. As stated in 2007 to the UN Economic and Social Council's Operational Activities Segment by Ad Melkert, UN Under-Secretary General and United Nations Development Programme (UNDP) Associate Administrator, the issue and concerns of $\mathrm{CD}$ should not be limited to a conversation on concept and theory:

Capacity development gives primacy to national priorities, plans, policies and processes. It underpins a shift from a technical assistance supply driven approach to an endogenous led process of change, and gives tangible form to the principle of national ownership. ... capacity development is the business of all governments, non government entities, civil society and the UN development system.

This is a clear statement on the importance of CD. The UNDP has also suggested ten principles for $\mathrm{CD}^{(5)}$. CD in this context is understood as the creation of an enabling environment with appropriate policy and legal frameworks, institutional development, including community participation, human resources development and strengthening of managerial systems. CD is a long-term, continuing process. The ten principles are as follows.

1. Don't rush. CD is a long-term process.

2. Respect the value system and foster self-esteem.

3. Scan locally and globally; reinvent locally. This implies there are no blueprints; knowledge cannot be transferred, it needs to be acquired.

4. Challenge mindsets and power differentials. Frank dialogue and a collective culture of transparency are essential.

5. Think and act in terms of sustainable capacity outcomes. Capacity is at the core of development; any course of action needs to promote this.

6. Establish positive incentives. Motives and incentives need to be aligned with the objective of CD.

7. Integrate external inputs into national priorities, processes and systems. External inputs need to correspond to real demand and be flexible enough to respond to national needs and agendas.

8. Build on existing capacities rather than creating new ones. This implies using national expertise primarily, strengthening of national institutions, and protection of social and cultural capital.

9. Stay engaged under difficult circumstances. People should not be held hostage to irresponsible governance.

10. Remain accountable to ultimate beneficiaries. Any responsible government is answerable to its people and should foster transparency as the foremost instrument of public accountability.

The purpose of the current paper is to present the evolution of a network for CD in nutrition in Central and Eastern Europe (CEE), delineate its content, and assess its activities to date against the UNDP principles as a reference standard.

\section{Evolution and challenges of the Central and Eastern European network for capacity development in nutrition}

The most recent UNU/SCN-initiated regional CD network is in the CEE region. A networking of training and research institutions was regarded as significant, and a regional approach was seen as needed to strengthen and maintain regional agendas and organization.

In 2005 a meeting was held in Budapest, Hungary to initiate processes which finally led to the establishment of the SCN/UNU Network for Capacity Development in Nutrition for Central and Eastern Europe (NCDN-CEE; referred to hereafter as 'Network'). The objective was to initiate and support CD activities in research and training in CEE countries. This was part of the effort of the SCN/ UNU WG to catalyse the formation of regional networks working towards the enhancement of individual, institutional and organizational capacity in food and nutrition.

Two subsequent Network meetings took place in 2006 and one in $2007^{(6-10)}$. In addition, the Network participated in the annual sessions of the SCN, and a small informal steering committee has met whenever convenient (conferences, etc.). The Network's activities, results and plan of the work were presented at several international meetings and collaboration on CD has been established ${ }^{(11-15)}$.

Participants over the last two years came from ten countries: Albania, Bosnia and Herzegovina, Bulgaria, Czech Republic, Macedonia, Hungary, Romania, Serbia and Slovakia, and facilitators came from The Netherlands and Norway.

\section{Food and nutrition needs and challenges}

Nutritional and lifestyle-related public health problems were among issues addressed by the Network. In group work, the main characteristics of nutrition and lifestyles in the region were delineated, as well as how these were linked to, for example, irregular meal patterns, low intakes of fruits/vegetables, milk products and fish, high intakes of total fat, sugar and salt, low intakes of vitamins and minerals, high levels of alcohol intake and low 
breast-feeding rates ${ }^{(6,8)}$. There was a similar profile in all countries, although with variations in precise manifestations in the individual countries.

Nutrition and lifestyle characteristics were linked to well-known public health problems such as the high prevalence of non-communicable diseases (hypertension, atherosclerosis, CHD, chronic venous insufficiency), certain cancers and diabetes mellitus, high levels of overweight and obesity, dyslipidaemia, micronutrient deficiencies, Fe-deficiency anaemia, low levels of physical activity, increasing osteoporosis, increase in eating disorders, and high levels of smoking ${ }^{(6-12,16-20)}$. Good data on these challenges seemed to be inadequate.

The approach to the problems was found to vary across the CEE region. The Network therefore identified some main challenges for policies, programmes and activities and pointed to what was being done to meet them. The discussion included the following topics.

1. Limited interaction between ministries, governmental organizations and the scant existence of policy documents, a consequence of, or linked to, the political system. This came forward in the discussions, and it was the opinion of the participants that it resulted in insufficient engagement in issues related to food, diet and nutrition. This seems to be caused by low priority in policies; lack of national nutrition strategies or action plans; and lack of coordinated nutritional activities, such as monitoring. This was the general situation, but with some exceptions and variations between countries. This pointed to the possibility to address nutrition challenges in communities, which requires a long-term perspective.

2. National nutrition action plans. Several countries had recently developed plans or are in the process of formulating them.

3. Food-based dietary guidelines were considered important for all countries, and several had such guidelines.

4. Recommended Dietary Allowances (RDA) were considered normative documents and the responsibility of governments, and several countries had them.

5. Food databases were considered essential for any type of dietary assessment, nutrition epidemiology, monitoring, and policy planning and assessment. Not all countries had food databases, and some national databases were based on other countries' compilations.

6. Academic training of professionals. Higher training and education in nutrition is a prerequisite for policy, strategy and programme development. Such training was modest in many countries, and only a few countries had specific education for nutritionists. This weakness was considered a major challenge. Currently nutrition is only part of other training (such as specialization in hygiene), which is a heritage of the previous political system. At present there is a lack of 'pure' academic nutrition education; there is inadequate knowledge of nutrition among medical specialists, insufficient training in nutritional epidemiology, inadequate clinical nutrition training, inadequate curricula of nutrition in medical faculties, inadequate knowledge of nutrition among health professionals working with the population, lack of in-service training of nutrition, and generally a lack of or inadequate methodological approaches and software for data collection, assessment and analyses ${ }^{(6-12,14)}$.

7. Education and promotion of the public is one of the most frequently used approaches to influence nutrition awareness of the population, which in most countries was not sufficiently well-organized and planned.

\section{What can be done in Central and Eastern European countries?}

Issues that could be part of a common strategy were identified. They included nutrition education at university level and common training courses, including in-service training; pilot projects to address issues such as approaches in school canteens to improve the quality of school meals; and continued development of national food and nutrition policies and action plans, including dietary guidelines for different population groups. There is a need for using standardized RDA applicable for all countries in Europe. In order to get a scientifically good database for this, one needs to stimulate standardization of nutritional monitoring in the region. Establishing relevant web pages for exchange and collaboration between countries in the CEE was listed as important ${ }^{(6-12,14,15)}$.

\section{From needs to framework and recommendations}

It became clear that a framework was needed where the requirements of various actors were specified. The framework developed (Fig. 1) suggests four different levels of actors, including at governmental, institutional, education and community* level $^{(6-12,14)}$.

The governmental level includes primarily parliament, different ministries, policy makers/civil servants and local-level authorities. They are responsible for policy development (food security, nutrition, health and training) and are the main decision makers. These actors are also responsible for legislation, including protecting, promoting and supporting the human right to adequate

\footnotetext{
* We realize that the word 'community' is perceived in various ways throughout the world. Here, this word depicts local-level organizations. It should not be understood as limited to those members who have certain circumstances of nativity, religion or pursuit common to them, but not shared by those among whom they live. In the present context, all people living in a local area are seen as belonging to a community.
} 


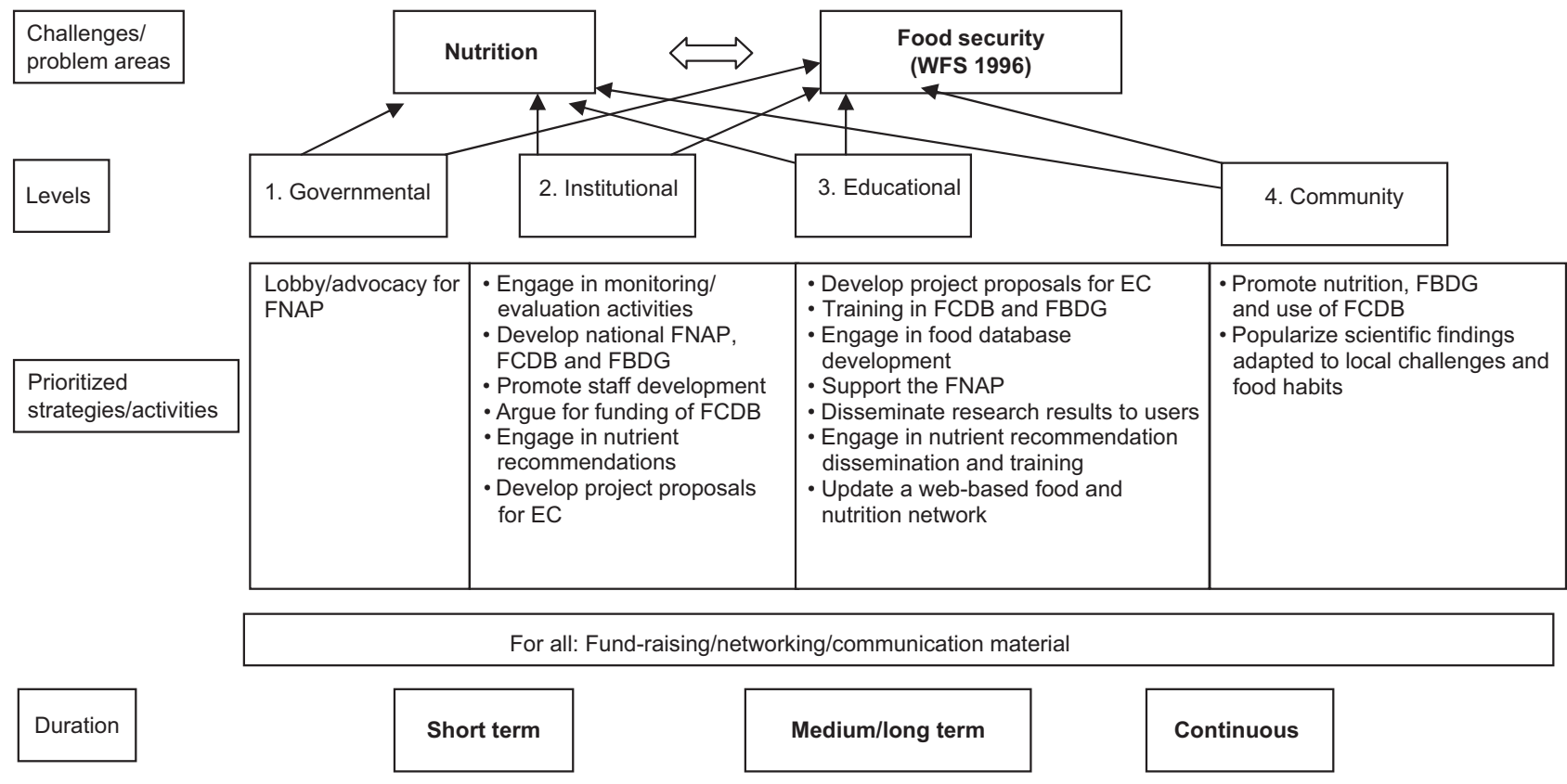

Fig. 1 Framework for challenges, levels of actors, prioritized strategies and activities, and time perspectives in nutrition in CEE countries (CEE, Central and Eastern Europe; EC, European Commission; WFS, World Food Summit; FNAP, Food and Nutrition Action Plan; FCDB, Food Composition Database; FBDG, Food-Based Dietary Guidelines)

food and education, national action plans, and for funding, monitoring and evaluation. Actors at institutional level include those working in public health and research institutions, health clinics, food control, agriculture extension and hygiene. Their main responsibility is to implement programmes or projects, provide expertise and advisory functions, ensure evidence-based knowledge gathering (research), maintain and develop staff capacity, adapt strategies to local needs, monitor and evaluate, provide feedback to ministries, and international collaboration.

At educational level, universities with their academic staff are considered the main actors providing advice and qualified personnel to governmental level, but also include school teachers at primary and secondary level, kindergarten personnel and catering staff. They have the main responsibility to implement policies on nutrition education at all levels, provide and support staff development, base education on local needs, evaluate, provide feedback and advise ministries, engage in international collaboration, and publish educational materials. At community level the main responsibilities are related to the production of safe and healthy foods, the marketing and promotion of healthy nutrition, positive role models in healthy eating and lifestyles, making informed choices, promotion of consumers' rights, assessing price levels of foods, and compliance to legislation.

A timetable was also considered, but difficult to delineate. However short-term, medium-term and longterm perspectives were needed, but the situation of each country and the urgency of the existing nutrition-related health challenges also needed to be taken into account.
Taking this situation into consideration, special attention should be given to negative transitions, addressing the higher nutrition education challenge of professionals and presenting adequate information to the population. Furthermore, research should be increased, including the development of food databases, nutrient recommendations and food-based dietary guidelines. Research should be harmonized, and the nutrition situation evaluated and monitored $^{(6,8-12,14)}$. This is in line with recommendations from the WHO, both centrally and regionally for Europe $^{(21,22)}$, and with European Commission (EC) White Paper on A Strategy for Europe on Nutrition, Overweight and Obesity related health issues ${ }^{(23)}$.

It was concluded that the Network should establish partnership and links to other activities, such as EC Projects. Several of the Network members are therefore partners in various EC-funded projects ${ }^{(13,14,24)}$.

\section{Reflections on the process and sustainability of the Network}

The ten principles for $\mathrm{CD}$ highlighted by $\mathrm{UNDP}^{(5) *}$ are used here to assess the Network's activities. The principle Don't rush (P1) was relevant. It was acknowledged by the participants that long-term activities would be needed,

* Understood here to include the creation of an enabling environment with appropriate policy and legal frameworks, institutional development, including community participation, human resources development and strengthening of managerial systems. The numbers in the text point to each of the ten principles. 
and for the Network it was important to have outside actors supporting the process.

The principle Respect the value system and foster selfesteem (P2) was taken into account during the process. It built upon respect and valued the self-esteem of the participants. This value should be part of the follow-up process and would be a reminder for the participants and facilitators.

Scan locally and globally; reinvent locally (P3) is a principle indicating that there are no blueprints. It was recognized that knowledge cannot just be transferred, but needs to be acquired through active participation in research projects and networks. Therefore it was considered important to be part of EC-initiated projects. EuroFIR* regional training courses, workshops and training exchange visits will be developed ${ }^{(14)}$. Another good example is the special EuroFIR edition of an existing Food Composition course. A special EURRECA $\dagger$ edition of a Nutrition and Lifestyle Epidemiology course for CEE countries, based on their needs, will be developed $^{(9,24)}$.

It was sensed that the participants were frank and transparent in their dialogues in line with the principle Challenge mindsets and power differentials (P4), and that there is a respect for the variation in culture of the various countries. These differences can be a positive force in further Network developments.

Think and act in terms of sustainable capacity outcomes (P5) indicates that sustainability is central to any type of initiated positive process, and CD is at the core of that development. This is an underlying dimension of the Network, and is something the Network will give priority to in the future.

In line with the principle of Establish positive incentives (P6), participation in the Network is seen as an incentive and the aims of CD highlight the professional needs felt by the participants. Another incentive is to be part of larger initiatives of the EC and beyond. This links professionals together, making them part of a larger professional society.

The principle Integrate external inputs into national priorities, processes and systems (P7) is at the core of the Network idea. External inputs to the Network correspond to real demand in the CEE countries. It is the professionals in these countries who have a strong influence on identifying and highlighting national needs, identifying the training activities and formulating agendas.

The principle Build on existing capacities rather than creating new ones (P8) is obvious. It is precisely national experts who participate, and thereby strengthen their national institutions. They will also bring elements of the

* The EC-funded project EuroFIR: The European Food Information Resource Network.

$\uparrow$ The EC-funded project EURRECA: The European Micronutrient Recommendations Aligned. social and cultural capital that exist in their countries into the Network.

The principle Stay engaged under difficult circumstances (P9) goes without saying. The participants have been through changes and political turmoil which prove that their participation is in spite of the political situation. There is a gradual change in the region that also will spill over to the political scene. In some countries this has happened already; in others there are signs that it will happen in the future.

The implication of the principle Remain accountable to ultimate beneficiaries (P10) is somewhat too early to see now, but any responsible government is accountable to its people and should foster transparency as the foremost instrument for accountability. The Network participants see the uneven unsatisfactory governance, but see also that learning from the various countries by exchanging ideas and experiences can enrich the coming development. Each country has its own way to go; time is needed and the direction will be important. The Network participants will maintain pressure points for a future inclusive accountability system, based on each country's cultural identity and political culture.

The experiences with this Network have shown the important role of external inputs, but with a firm hand on the wheel by regional and national professionals themselves. By having the UNDP principles clear in the mind of those developing the Network further, this initiative may play a more crucial role than initially expected. The Network has already highlighted the need for capacity building in nutrition in the CEE region, and should become an efficient tool in mobilizing and streamlining further regional involvement.

\section{Acknowledgements}

The work was supported by the UNU-FNP; the Ministry of Science and Environment Protection, Republic of Serbia (grant no. 145071); EuroFIR; EURRECA; the Norwegian Government; and the FAO Sub-Regional Office for Central and Eastern Europe, Budapest. There is no conflict of interest. M.P. is the main author and Principal Investigator; she is the leading author of the paper together with A.O. They structured the paper, and she summed up the situation in the CEE countries. She developed the framework in Fig. 1 together with A.O., based on input and feedback from the other authors. A.O. brought in the UNDP document that suggested the ten principles for capacity development. F.P. contributed with the historical issues of the SCN Working Group on Capacity Development. M.D. wrote part of the general assessment since he is particularly knowledgeable about the situation in CEE countries. L.B., P.S., Z.D., V.D., C.P. and A.F.H. each wrote parts of the assessment of the situation in respective countries, which now forms part of the text of the figure and the text under "What can be done 
in Central and Eastern European countries?' They also participated to the text under 'From needs to framework and recommendations' and contributed to editing and proofreading. M.G. worked with M.P. on analysing and presenting data from Serbia.

\section{References}

1. Rogers B \& Schlossman N (1997) 'Public nutrition': the need for cross-disciplinary depth in the education of nutrition professionals. Food Nutr Bull 18, 120-133; available at http://www.unu.edu/Unupress/food/vi82e/ index.htm

2. Garza C (2004) Newsletters of the SCN Working Group on Capacity Development in Food and Nutrition. http://www. unsystem.org/scn/Publications/AnnualMeeting/capacity_ development_newsletters.htm (accessed December 2008).

3. UNU/SCN Working Group on Capacity Development in Food and Nutrition (2006) Report/Planned Activities. http://www.unsystem.org/scn/Publications/AnnualMeeting/ SCN33/33_capacitydev.htm (accessed December 2008).

4. Pepping F (2006) Diet related chronic diseases and double burden of malnutrition in West Africa. UNU/IUNS Nutrition Capacity Building in Africa. SCN News 33, 39-42.

5. Lopes C \& Theisohn T (2003) Ownership, Leadership and Transformation. Can We Do Better for Capacity Development? London: Earthscan Publications Ltd.

6. Pavlovic M (2006) Report of the inauguration meeting of the Network for Capacity Development in Nutrition Central and Eastern Europe, Budapest, 13-14 February. http:// www.srbnutrition.info/?page $=$ Network $($ accessed December 2008).

7. Pavlovic M (2006) CEE Countries Capacity Development Network Newsletter I (March 2006). http://www.unsystem. org/scn/Publications/AnnualMeeting/Activities\%20in\%202006 CEE\%2029march0611.doc (accessed December 2008).

8. Pavlovic M, Pepping F \& Oshaug A (2006) Capacity Development in Nutrition in Central and Eastern Europe - Report from the inaugural meeting of the Network on Capacity Development in Nutrition in CEE countries. 33rd SCN meeting, Geneva, March. http://www.unsystem.org/ scn/Publications/AnnualMeeting/SCN33/WG_capacity_ development/2006_CEE_network.ppt (accessed December 2008).

9. Pavlovic M, Pepping F \& Oshaug A (2006) Report of the 2nd meeting of the UNU/SCN Network for Capacity Development in Nutrition Central and Eastern Europe: NCDN CEE, Budapest, 16-17 November. http://www. srbnutrition.info/?page $=$ Network (accessed December 2008).

10. Pavlovic M, Pepping F \& Oshaug A (2007) Report of the 3rd meeting of the UNU/SCN Network for Capacity Development in Nutrition Central and Eastern Europe (NCDNCEE), Belgrade, 1-2 November. http://www.srbnutrition.info/ ?page $=$ Network $($ accessed December 2008).

11. Pavlovic M, Pepping F \& Oshaug A (2007) Report of the Network for Capacity Development in Nutrition in Central and Eastern Europe. 34th SCN Meeting, Rome, 28 February. http://www.srbnutrition.info/?page $=$ Network $\quad$ (accessed December 2008).

12. Pavlovic M, Glibetic M, Pepping F, Biro L \& Oshaug A (2006) Network for Capacity Development in Nutrition (NCDN) in CEE. Abstracts of the 1st World Congress of Public Health Nutrition, Barcelona, 28-30 September 2006. Public Health Nutr 9, 162
13. Working Group on Capacity Development in Food and Nutrition Agenda (2007) Capacity Development in Food and Nutrition Working Group Task Force Reports: Past, Present, Future. Report of the inauguration meeting of the Network for Capacity Development in Nutrition Central and Eastern Europe, Dr Mirjana Pavlovic. http://www. unsystem.org/scn/Publications/AnnualMeeting/SCN34/34_ capdev.htm (accessed December 2008).

14. Pavlovic M, Pepping F, Michal D, Biro L, Szabolcs P, Dimitrovska Z, Duleva V, Parvan C \& Oshaug A (2007) Capacity development in public nutrition: a network in Central and Eastern Europe (NCDN-CEE). Abstracts of the 10th European Nutrition Conference, Paris, 10-13 July. Ann Nutr Metab 51, Suppl. 1, 324.

15. Pavlovic M, Finglas P, Witthöft C et al. (2007) A partnership between Network for Capacity Development in Nutrition (NDCN-CEE) in Central and Eastern Europe and European Food Information Resource Network (EuroFIR). Abstracts of the 10th European Nutrition Conference, Paris, 10-13 July. Ann Nutr Metab 51, Suppl. 1, 322.

16. UN System Standing Committee on Nutrition (2004) The Fifth Report on the World Nutrition Situation: Nutrition for Improved Development Outcomes. http://www.unsystem. org/scn/Publications/AnnualMeeting/SCN31/SCN5Report. pdf (accessed December 2008).

17. Pavlovic M, Kadvan A \& Vukotic M (2005) The quality of schoolchildren's nutrition in Serbia. In Early Nutrition and Its Later Consequences: New Opportunities, Perinatal Programming of Adult Health - EC Supported Research [B Koletzko, P Dodds, H Akerblom and M Ashwell, editors]. Adv Exp Med Biol 569, 212-213.

18. Pavlovic M, Prentice A, Thorsdottir I, Wolfram G \& Branca F (2007) Challenges in harmonizing energy and nutrient recommendations in Europe. Ann Nutr Metab 51, 108-114.

19. Pavlovic M, Grujic V \& Oshaug A (2006) Nutrition and physical activity of the population in Serbia. In Nutrition and Fitness: Obesity, The Metabolic Syndrome, Cardiovascular Diseases, and Cancer [AP Simopoulos, editor]. World Rev Nutr Diet 94, 51-59.

20. Robertson A, Tirado C, Lobstein T, Jermini M, Knai C, Jensen JH, Ferro-Luzzi A \& James WPT (editors) (2004) Food and Health in Europe: A New Basis for Action. WHO Regional Publications European Series no. 96. Copenhagen: WHO Regional Office for Europe; available at http:// www.euro.who.int/document/e78578.pdf

21. World Health Organization (2004) Global Strategy on Diet, Physical Activity and Health. Geneva: WHO; available at http://www.who.int/dietphysicalactivity/strategy/eb11344/ strategy_english_web.pdf

22. World Health Organization Regional Committee for Europe (2007) Proposed Second WHO European Action Plan for Food and Nutrition Policy 2007-2012. http://www.euro. who.int/document/rc57/edoc10.pdf (accessed December 2008).

23. Commission of the European Communities (2007) White Paper on A Strategy for Europe on Nutrition, Overweight and Obesity related health issues. http://ec.europa.eu/ health/ph_determinants/life_style/nutrition/documents/ nutrition_wp_en.pdf (accessed December 2008).

24. Pavlovic M (2007) Possible links between EURRECA and Network for Capacity Development in Nutrition in Central and Eastern Europe (NCDN CEE). 1st Meeting of the Steering Committee EURRECA, Brussels, 9 February. http://www.srbnutrition.info/?page $=$ Network $\quad$ (accessed December 2008). 